\title{
Revitalização das praças nas quadras 700: um exercício de projeto
}

\author{
Revitalization of squares in 700: a exercise of \\ project
}

Junia Marques Caldeira' Ana Luiza Padrão ${ }^{2}$
1 Arquiteta, Professora de Teoria e História, Projeto Urbano e de Arquitetura do UniCEUB, Brasília, DF. Graduada em Arquitetura e Urbanismo na UFMG. Doutora pelo Programa de pós-graduação em História do Instituto de Filosofia, Ciências e História da Universidade Estadual de Campinas.

2 Arquiteta, Graduada em Arquitetura e Urbanismo, pelo Centro Universitário de Brasília, 2013.

\section{Resumo}

O artigo tem como objetivo abordar o tema dos espaços públicos das quadras 700, área residencial situada em Brasília e desenvolvida posteriormente à implantação do Plano Piloto de Lucio Costa. (CARPINTERO, 1998). Esta área com perfil residencial foi idealizada para complementar o setor de moradias projetado nas regiões das Asas Sul e Norte, bem como nos Lagos Sul e Norte da cidade. Atualmente, apesar de manterem a configuração original, as quadras 700 passam por uma mudança de perfil com o crescimento dos setores de comércios, serviços e institucionais que margeiam essas regiões. Os espaços públicos, sobretudo as praças existentes, tornaram-se gradativamente espaços degradados e abandonados, mas que ainda permanecem como áreas livres para uso coletivo. Dessa forma, o trabalho final realizado para a conclusão do Curso de Arquitetura da aluna Ana Luiza Vasconcelos Padrão Ribeiro - Praça das Gerações - propõe uma leitura da área, ao mesmo tempo em que se torna um exercício de projeto, no sentido de estabelecer parâmetros para uma intervenção de revitalização das praças das quadras 700. Neste sentido, o artigo se desenvolve a partir do estudo sobre o papel dos espaços públicos idealizados por Lucio Costa, no Plano Piloto; com destaque para a configuração das quadras 700; o diagnóstico do modelo de praças das 700; e os parâmetros essenciais para uma requalificação que possa notadamente proporcionar condições de uso e de reapropriação dessas praças pela comunidade do entorno e de habitantes em geral.

Palavras-chave: Revitalização. Praças. Espaço Público.

\begin{abstract}
This article aims to address the issue of public spaces in a residential area of Brasilia, which developed in a period subsequent to the implementation of the Pilot Plan, authored by architect Lucio Costa. This area was designed to complement the residential sector projected in regions known as South Wing and North Wing, as well as residential areas located in South Lake and North Lake of Brasilia. Currently, despite keeping the original configuration, this region, known as the 700 blocks, pass through a change of usage profile as a result of the growth of trade, services and institutional usage. Public spaces, especially the existing plazas became gradually degraded and abandoned, but still remain as open spaces for common use. This work originated in a monograph held for the conclusion of the course of architecture of the student Ana Luiza Ribeiro Vasconcelos Standard, with the title "Generations Square". The paper proposes an evaluation of this area, and an exercise to establish parameters for an intervention to revitalize the squares located in this area. The starting point of the article was a study on the role of public spaces conceived by Lucio Costa, in the Pilot Plan, with emphasis on the setting of "700 blocks". It was also performed a diagnosis model and area of squares of the essential parameters for a redevelopment that can notably provide conditions of use and appropriation by the surrounding community and its inhabitants.
\end{abstract}

Keywords: Revitalização. Praça publica. Espaço Público. 


\section{Introdução}

Na concepção do Plano Piloto de Brasília, Lucio Costa organizou a cidade a partir de quatro escalas: a coletiva ou monumental; a concentrada ou gregária; a cotidiana ou residencial; e posteriormente a escala bucólica, correspondendo à dimensão ambiental, aos espaços verdes e aos ajardinados que permeiam todas as outras. Cada uma dessas escalas deveria interagir entre si, resguardando, portanto, suas características distintas. A partir desse princípio, o projeto esboçava um novo desenho de cidade. (COSTA, 1957)

Esse desenho urbano apresentava uma espacialidade marcada, notadamente, pela ruptura com a morfologia da cidade tradicional. Destaca-se a relação espaço livre versus parcelamento tradicional, baseada na recusa da configuração do lote em favor da ideia de espaço contínuo ocupado por edificações laminares.

Figura 1 - Plano Piloto de Brasília proposto por Lucio Costa

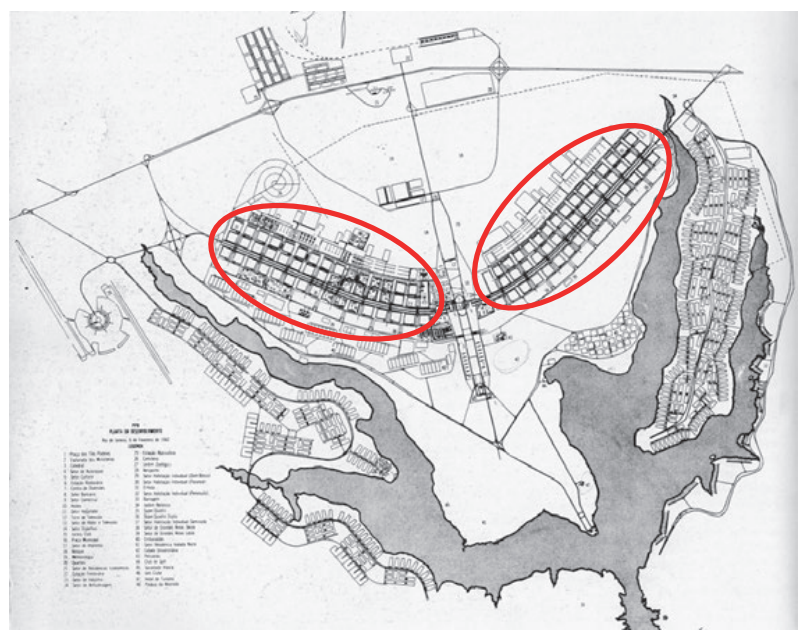

Fonte: (COSTA, 1995)

Na proposta de Lucio Costa, a escala residencial se organizava em torno do modelo de habitações coletivas e individuais. Esta área aparecia dividida em duas regiões distintas: uma consistia nos setores habitacionais situados ao longo dos eixos rodoviários, norte e sul; e a outra, no setor de loteamentos de casas individuais, norte e sul, próximos à zona do lago.

O principal setor habitacional, localizado ao longo do eixo rodoviário, foi elaborado segundo a lógica da unidade de vizinhança. ${ }^{3}$ As áreas de vizinhança eram for-

3 Na década de 1920, um importante grupo interdisciplinar (RPAA - Clarence Perry, Clarence Stein, Henry Wright, Catherine Bauer, Frederick Akermann, Lewis Munford, madas por núcleos subdivididos em quadrados fechados e denominados de superquadras. Uma unidade de vizinhança consistia no agrupamento de quatro superquadras.

Figura 2 - Esquema das superquadras distribuídas ao longo do eixo

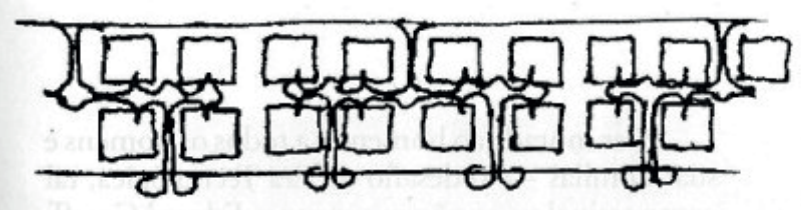

Fonte: (COSTA, 1995)

\section{As quadras 700}

Em sua concepção original, o setor residencial das superquadras estava destinado a oeste do eixo rodoviário, compondo as quadras 100, 300 e 500; a leste existia somente uma fileira de quadras, as 200 . As quadras 600, 400, 700 e 900 foram acrescentadas posteriormente, devido à necessidade de expansão residencial e à acomodação de famílias de menor poder aquisitivo. Esta expansão do setor residencial deu origem às quadras de Habitações Individuais Geminadas Sul - SHIG, quadras 700 - permeadas por espaços livres, constituindo as entrequadras das faixas 700. (CARPINTERO, 1998)

Esse espaço fora, originalmente, reservado para floriculturas, hortas e árvores frutíferas; no entanto, no processo de implantação da cidade, esta grande área livre que acompanhava as duas Asas do Plano Piloto foi sendo ocupada por habitações geminadas. ${ }^{5}$

Em 1958, esse setor foi inaugurado com a construção de 500 casas geminadas, ocupadas em sua maioria

entre outros) desenvolveu, nos Estados Unidos, o que seria um modelo de núcleos urbanos autossuficientes imersos em áreas verdes. $\mathrm{O}$ arquiteto Clarence Arthur Perry seria o responsável pelo ensaio intitulado Neighbourhood Unit (1929), cujo estudo centrava-se no problema das unidades habitacionais e nos serviços necessários e essenciais ao seu bom funcionamento. Dessas experiências, podemos destacar os projetos dos arquitetos Clarence Stein e Henry Wright: Sunnyside Gardens (1924), Radburn (1928), Greenbelt (1935) e Gravagnuolo (1998). Para mais aprofundamento no tema, ver Sica (1978), Ragon (1986b), Calabi (2000), Barcellos (2001) e Ferreira e Gorovitz (2007).

4 A própria Companhia Urbanizadora da Nova Capital (Novacap), com a supervisão de Lucio Costa, propôs essas modificações.

5 O perfil das quadras 700 Sul permanece essencialmente residencial, já as quadras 700 Norte diferem quanto ao uso, pois nelas se encontram áreas comerciais e residenciais (inclusive prédios). 
por técnicos e funcionários dedicados à construção da cidade de Brasília. O projeto de autoria de Oscar Niemeyer contava com conjuntos de seis a oito casas geminadas, (FERREIRA; GOROVITZ, 2008) ${ }^{6}$ intercaladas por áreas livres e praças.

Figura 3 - Panorama das quadras 700, em 1964.

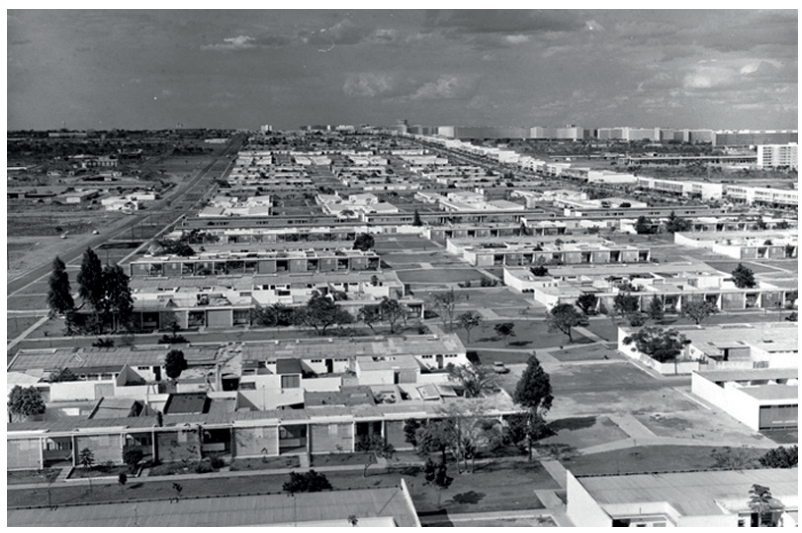

Fonte: Arquivo Público do Distrito Federal (1964)

Segundo Frederico Flósculo (2013), ${ }^{7}$ as quadras 700 sul foram ocupadas inicialmente pelas famílias dos engenheiros que trabalhavam na construção da cidade. Os conjuntos de casas geminadas (SHIGS, na Asa Sul, e posteriormente SHCGN, na Asa Norte) nasceram como uma espécie de conjunto habitacional de pioneiros. Os primeiros proprietários estavam ligados à Novacap (Companhia Urbanizadora de Nova Capital do Brasil) e teriam alterado o uso para acomodar os "companheiros". (CALDAS et al., 2013)

Com o crescimento da cidade, nota-se que o perfil das habitações geminadas sofreu diversas mudanças, destacando-se questões de gabarito e afastamento. Em 1987, o Governo publicou uma série de normas construtivas Normas de Edificação, Uso e Gabarito (NGB) - com o objetivo de padronizar o crescimento urbano futuro. ${ }^{8}$

A implicação dessas normas para as quadras 700 resultou na determinação do gabarito construtivo a dois pavimentos acima do solo, não podendo ultrapassar sete metros de altura. Com este gabarito limitado, a Adminis-

6 Cada unidade habitacional térrea possuía sala, três quartos, banheiro, cozinha, área de serviço, varanda, pequeno jardim e quintal.

7 Professor da Faculdade de Arquitetura e Urbanismo (FAU) da Universidade de Brasília (UnB).

8 As normas da NGB de 1987 foram publicadas meses antes de Brasília ser tombada como Patrimônio Mundial pela UNESCO. tração visava evitar o processo de verticalização da cidade nesta escala residencial. ${ }^{9}$

Figura 4 - Gabarito construtivo atual

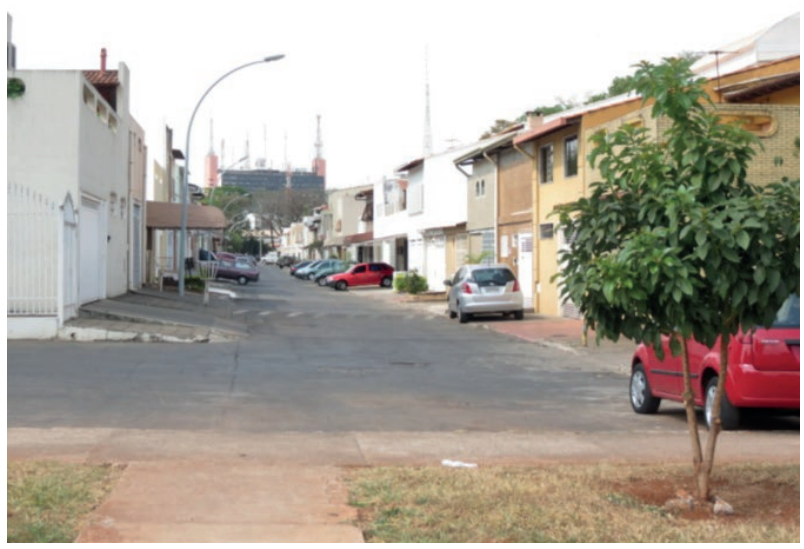

Fonte: Arquivo Pessoal (2013)

As escalas idealizadas para o Plano Piloto - monumental, gregária e residencial - foram abordadas por Lucio Costa de maneira distinta e determinaram transformações precisas na forma de apreensão dos espaços urbanos.

Em relação aos espaços destinados às praças, podemos observar que cada um deles apresenta um conceito diferenciado. Se no eixo Monumental a praça assume proporções de Acrópole, formando grandes cenários urbanos; na escala gregária, a função de acolhimento produz espaços de proporções reduzidas, típicos de praças tradicionais, capazes de distribuir e acolher o fluxo de pedestres. Quanto à escala residencial, o espaço da praça praticamente desaparece na trama da superquadra, substituído pelo conceito modernista de espaço livre, voltado para a realização de atividades de lazer dos moradores, com parques infantis e quadras de esportes.

A proposta de Lucio Costa tencionava possibilitar novas experiências urbanas, buscando modificar relações sociais e espaciais arraigadas ao uso tradicional da cidade em função de uma estética inovadora. Neste sentido, as praças idealizadas no projeto continham o germe de espaços tradicionais, materializados em uma nova morfologia: o espaço livre.

9 Devido à contínua descaracterização das quadras 700, com consequente desrespeito ao tombamento, o texto do Plano de Preservação do Conjunto Urbanístico de Brasília (PPCub), articulado em 2011, aumentou o limite de altura das edificações para 8,5 metros, embora mantenha o terceiro pavimento na ilegalidade. 
Nesse sentido, os espaços livres articulados às áreas residenciais das quadras 700 foram idealizados para serem apropriados aos seus residentes com áreas de lazer e encontro. As praças das 700 marcam a transição da Avenida W3 - escala gregária, local de comércio - para o interior das quadras residenciais.

Figura 5 - Praça do índio localizada entre as quadras 703 e 704 sul

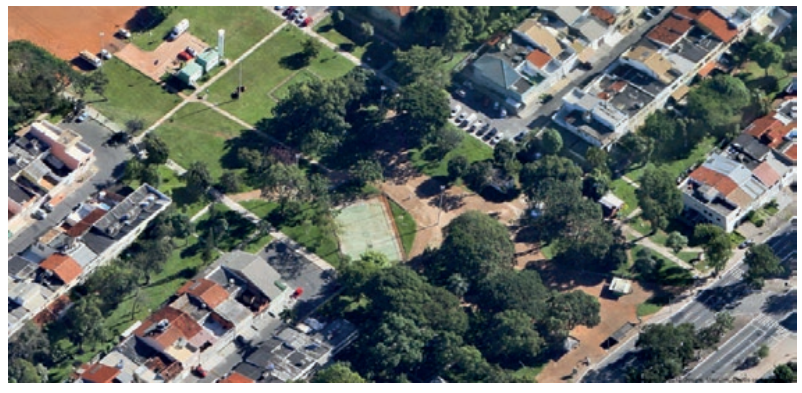

Fonte: Google maps (2013)

Com o processo de crescimento da cidade de Brasília, o setor das quadras 700 foi sendo afetado gradativamente pelo declínio das regiões da W3 Sul e Norte, avenidas marcadas pelo setor comercial desde o início da construção de Brasília.

Um estudo realizado para verificar as condições das áreas livres situadas na região das 700 sul apontou que a maioria das praças constitui espaços sem manutenção, impossibilitando seu aproveitamento como área de lazer e encontro. Embora algumas praças tenham sido "revitalizadas" por iniciativa do Governo, estas reformas estão longe de propiciar condições adequadas para o conforto dos usuários. Nota-se nestas iniciativas uma defasagem do projeto no sentido de buscar atender às necessidades dos usuários e promover encontros, permanência e convivência, propiciando a sociabilidade, características que se referem ao conceito de praça desde sua origem na Ágora Grega e no Fórum Romano.

\section{Praça das geraçôes: um exercício de projeto}

$\mathrm{O}$ interesse em trabalhar com as praças das quadras 700 teve origem nas experiências e lembranças de um tempo em que estas praças ficavam repletas de moradores e pessoas que buscavam lazer e contato com o ar livre. Entender a inserção de espaços de praças no cotidiano contemporâneo parecia um percurso correto para a criação de uma proposta de revitalização bem sucedida. ${ }^{10}$

10 A pesquisa sobre o tema teve início com um estudo de out-
Neste sentido, a escolha do tema como projeto final de graduação pareceu um excelente exercício para estudar a questão das praças e suas diversas possibilidades de apropriação, levando em consideração a dinâmica da cidade e as atuais necessidades dos usuários.

Para tal, foi escolhida a praça localizada nas entrequadras 705/706 Sul. O projeto teve como objetivo principal criar espaços que proporcionassem condições de um convívio saudável, alegre e acessível a todos que circulam no local. Além de resgatar a história e memória do lugar, promovendo o encontro de gerações que frequentaram e frequentam essa praça, assim como estimular o envolvimento social por meio da arquitetura e da afirmação da cidadania.

A praça da 705/706 está localizada em um terreno de aproximadamente 20 mil metros quadrados, é cercada pelas vias W3, W4 Sul e pelas quadras residenciais 705 e 706 Sul. A área comercial mais próxima se encontra na avenida $\mathrm{W} 3 \mathrm{Sul}$, e a área institucional situa-se próxima às vias W4 e W5 Sul, nas quadras 900.

Figura 6 - Situação atual da praça das Quadras 705 e 706 Sul

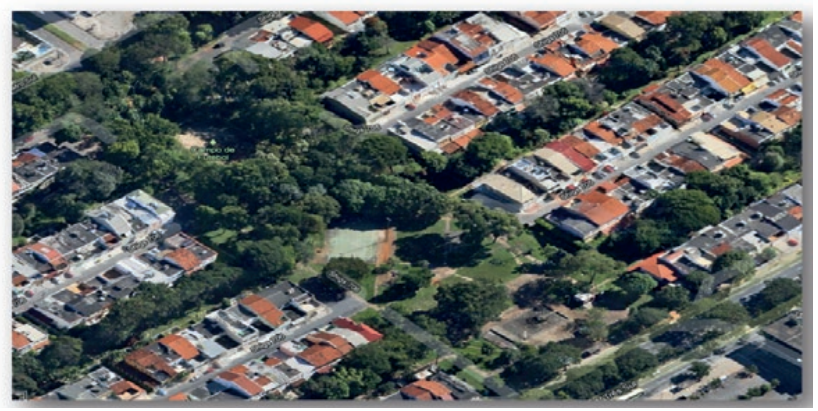

Fonte: Google maps (2013)

O estudo do local (ALEX, 2008) demonstrou que a situação da praça da 705/706 está como a maioria das praças de Brasília: equipamentos abandonados e degradados, bancos quebrados, espelhos d'água vazios e calça-

ras praças situadas em Brasília. Este estudo teve como base o livro "Projeto da Praça" de Sun Alex, cuja metodologia de análise baseia-se nas "conformidades", ou seja, as potencialidades do espaço e suas "não conformidades", isto é, as problemáticas encontradas. Foram elas: Praça Portugal, situada próxima à Embaixada de Portugal; Praça do Índio, localizada entre as quadras 703 e 704 Sul; e a Praça 21 de abril, entre as quadras 707 e 708 Sul. A não conformidade encontrada em todas elas foi a falta de manutenção e abandono dos equipamentos e mobiliário das praças, e a conformidade foi o valor simbólico de cada uma permanente na memória dos seus usuários. 
das em péssimas condições. As conformidades estavam relacionadas à existência de alguns equipamentos, como quiosques e banca de jornal, que atraem alguns usuários.

Figura 7 - Estudo das conformidades (em amarelo) e não conformidades (em vermelho), indicando as problemáticas do espaço da praça.

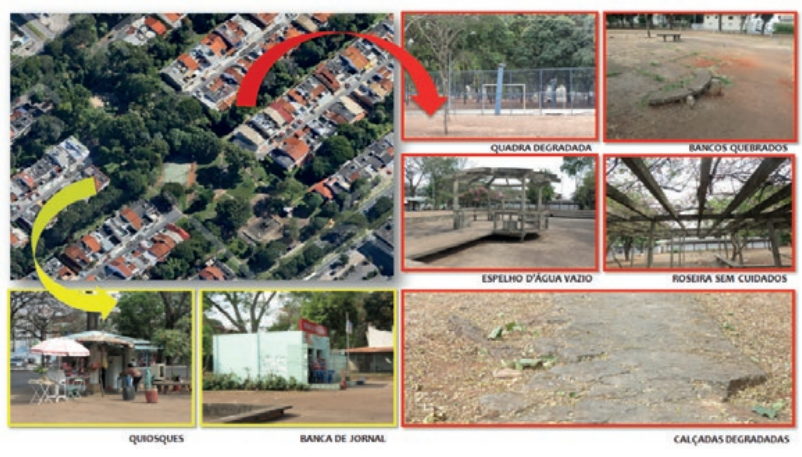

Fonte: Arquivo pessoal (2013); Google maps (2013)

Inicialmente buscou-se averiguar as necessidades dos moradores das quadras locais a partir de entrevistas, assim como da observação do espaço e de seus frequentadores. A partir desta pesquisa, foram geradas palavras-âncoras que auxiliaram na composição conceitual do projeto (permeabilidade, cultura, lazer, gerações, troca, permanência, história, juventude, idosos, contemplação, integração, reunião e segurança).

As necessidades sociais e culturais consolidadas mediante à evolução urbana permitiram introduzir novos elementos funcionais que definiram as praças contemporâneas. Em um projeto de intervenção urbana, é importante considerar que o cliente efetivo é a população que irá usufruir deste espaço. Neste sentido, é importante uma definição de programa que atenda aos interesses do grupo social. Sob esta ótica, buscou-se estabelecer um programa com as seguintes questões:

- resgatar a simbologia da praça por meio de desenho e de estruturas que valorizem e identifiquem seu espaço;

- incorporar a acessibilidade e a segurança, respeitando e valorizando o fluxo de pedestres;

- propiciar o acesso à internet wireless permanentemente, adequando a praça às necessidades atuais;

- utilizar mobiliário adequado aos diferentes usos, privilegiando espaços para a implantação de áreas de lazer ativo, como quadra de esporte e parque infantil;

- incorporar elementos que possam ser valoriza- dos pela população, como áreas de permanência: cafés, serviços etc.;

- incorporar um projeto paisagístico capaz de propiciar locais agradáveis e de sombreamento, explorando a composição de "lugares" e de paisagem, bem como propiciar a permeabilidade do solo;

- utilizar soluções estruturais simples, evitando, assim, que os locais se tornem perigosos e inseguros, com destaque para o projeto de iluminação;

- estabelecer um ponto focal que represente um elemento de referência no espaço da praça.

A setorização das atividades na Praça Gerações contempla:

- parque infantil;

- área de ginástica para idosos e jovens;

- área de esportes;

- área para contemplação;

- área de quiosques (incluindo banca de revista, sapateiro, floricultura, costureira etc.);

- bicicletário;

- edifício multifuncional (com salão de festas, sala de administração, banheiros públicos, café e livraria);

- posto policial;

- pistas de caminhada e caminhos acessíveis;

- elemento focal;

- marcação sobre o piso da praça;

A análise da configuração morfológica do entorno deu origem ao desenho e à conformação dos principais eixos de deslocamento e percursos no projeto. O partido urbanístico destaca a malha existente, propondo o prolongamento de caminhos e percursos já consolidados no local. Um eixo transversal acentua o acesso livre e se dirige ao ponto focal: o edifício cultural e anfiteatro.

Após a marcação do eixo principal, foi estabelecido o centro no espaço da praça. Isso significa marcar sua superfície, criando referências para o usuário. Segundo Jane Jacobs (2011), existem alguns parâmetros essenciais para a projetação de espaços coletivos: a centralidade, o limite, a diversidade de usos, as áreas de sombra e as áreas ensolaradas, além de um entorno pulsante que possa alimentar e gerar vivacidade ao espaço. Neste sentido, buscou-se aplicar ao desenho e ao programa da praça alguns desses parâmetros, estabelecendo um ponto central e fluxos de circulação diversos. A intenção foi criar caminhos 
de circulação rápida para os passantes e caminhos regulares e retilíneos para os usuários que desejassem usufruir do espaço da praça com certa permanência.

O eixo condutor é caracterizado pela regularidade e continuidade, formando um caminho que atravessa o interior da praça e conduz o pedestre à passagem por todos os seus espaços, permitindo ao usuário descobrir lugares e ter impressões diversas, pontuadas pelas atividades que lá acontecem.

Figura 8 - Marcação do ponto focal e eixo condutor

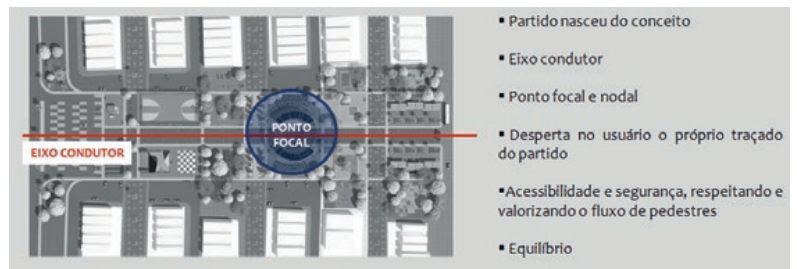

Fonte: Arquivo pessoal (2013)

O programa da praça contempla uma diversidade de atividades que inclui desde recreação, contemplação, área de jogos, encontros, até descanso. A vegetação, o mobiliário e os elementos edificados foram cuidadosamente trabalhados para dar conforto a cada espaço.

Figura 9 - Área de recreação e ginástica para jovens e idosos
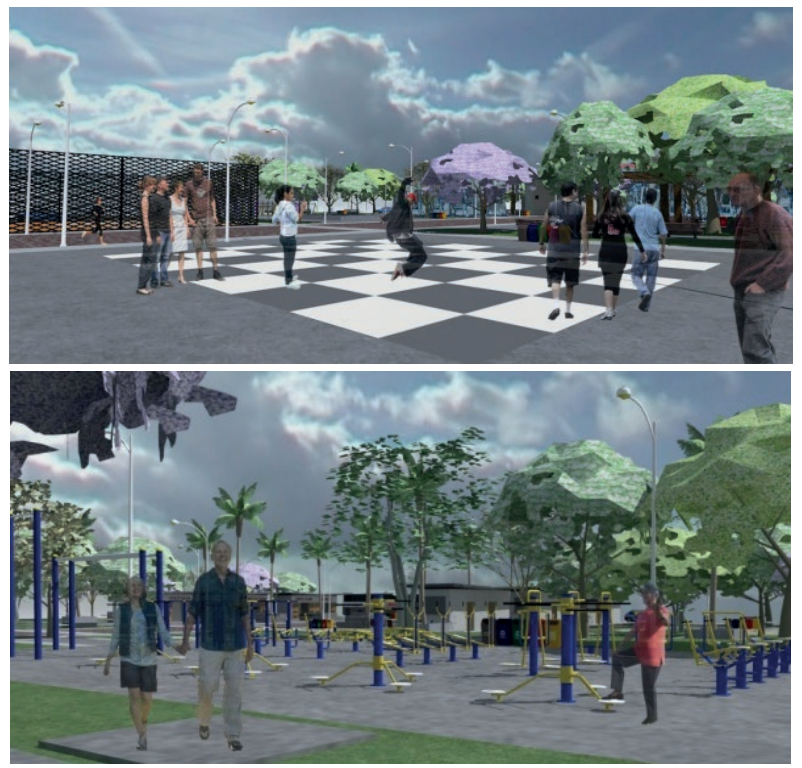

Fonte: Arquivo pessoal (2013)

As áreas lindeiras ao eixo principal foram organizadas segundo certa hierarquia funcional, que inicia com espaços de atividades gregárias, de maior densidade (atividades comerciais e serviços) e que termina com atividades específicas (pista de patins, quadra poliesportiva e horta suspensa).
Figura 10 - A Praça Gerações e suas atividades

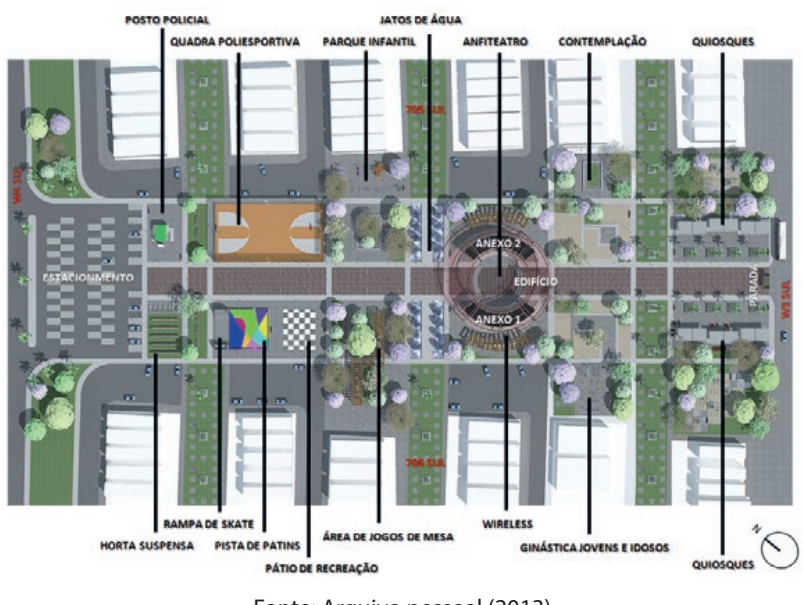

Fonte: Arquivo pessoal (2013)

Em sua superfície, optou-se pela utilização de elementos de indução, para que os transeuntes adentrassem no espaço. Tais elementos foram configurados a partir do ponto focal (edifício e anfiteatro) e de seu traçado, com pisos diferenciados e acessíveis, área destinada ao acesso livre à internet, quiosques e áreas de lazer para todas as idades. Desta forma, o espaço da praça configura-se de forma objetiva e simplificada. A iluminação visa proporcionar segurança, convívio e permanência durante o dia e a noite.

Figura 11 - Área de quiosques, mesa de jogos e parque infantil
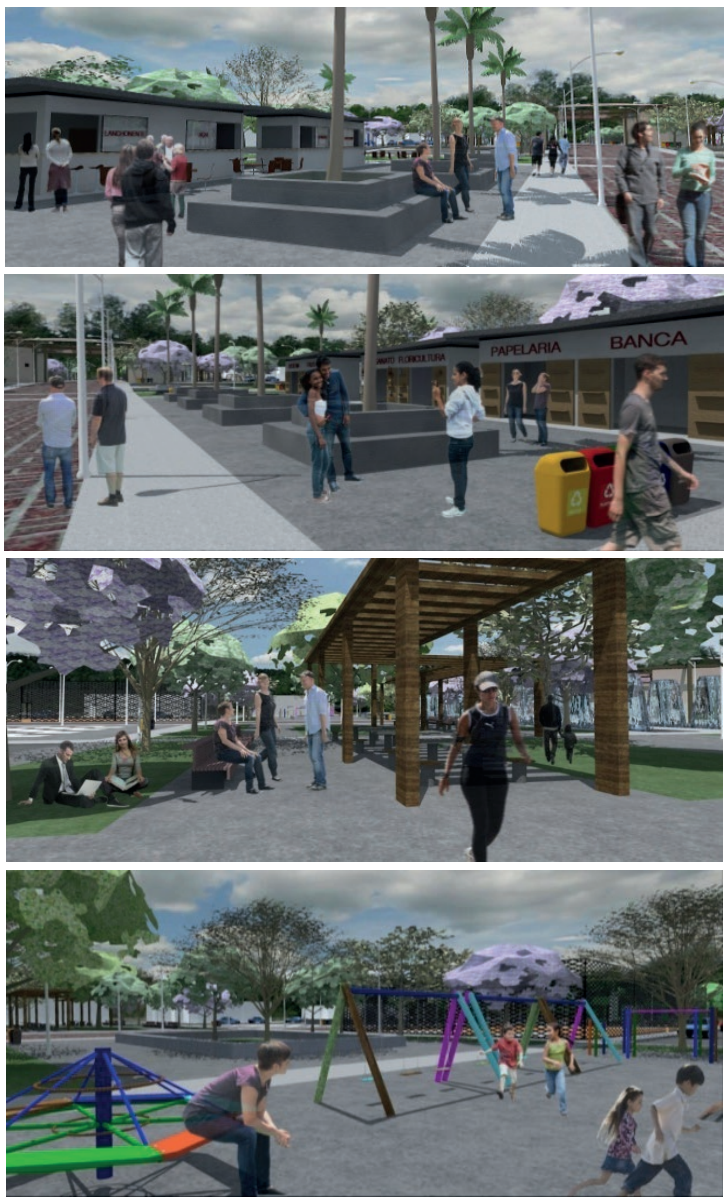

Fonte: Arquivo pessoal (2013) 
A utilização de pisos de superfícies regulares e antiderrapantes, bem como rampas, promove o conforto e a acessibilidade ao desenho universal, incentivando a frequência de pessoas com restrição de mobilidade total ou parcial.

O ponto focal foi constituído pela presença de uma edificação cuja volumetria curva rompe com o traçado regular característico do design da praça. O centro multifuncional foi idealizado com uma cobertura leve, em estrutura metálica e fibra de polipropileno, para permitir a continuidade visual do percurso principal. Fato esse que determinou a utilização dos dois blocos laterais, possibilitando o livre percurso sob essa cobertura. Um dos blocos abriga salão para festas, palestras e oficinas, área de apoio, copa e banheiros; e o outro abriga sala administrativa, livraria e café, área de apoio, depósito e banheiros públicos. No centro, um anfiteatro em nível inferior torna-se o ponto de encontro de várias gerações.

Figura 12 - Ponto forte do projeto: o edifício multifuncional

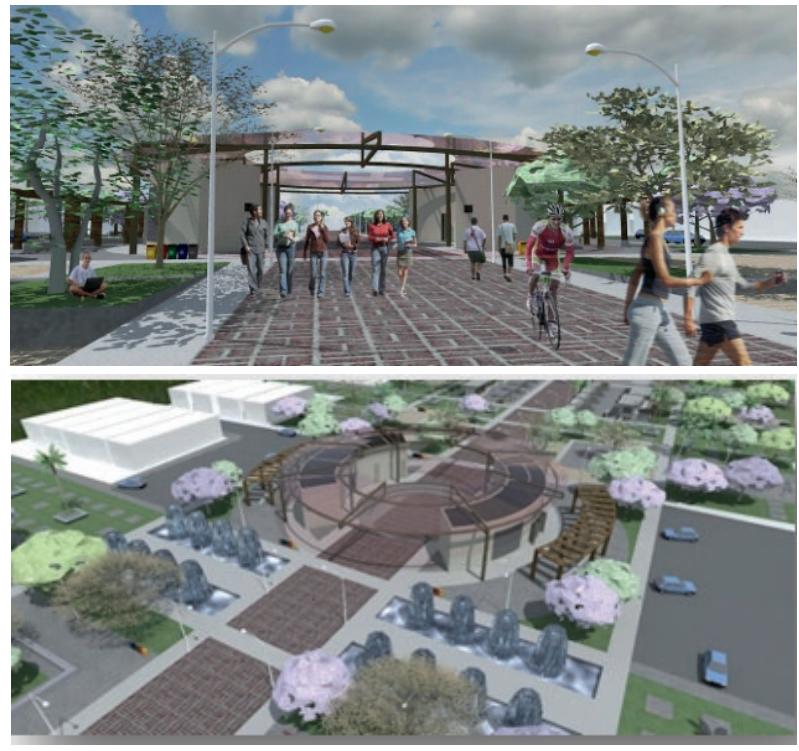

Fonte: Arquivo pessoal (2013)

\section{Considerações}

Buscou-se, a partir deste exercício de projetação - recuperação de um espaço público -, estabelecer parâmetros para uma abordagem contemporânea de usos e possibilidades das praças das 700 , no intuito de promover o ideal do domínio público, a apropriação diversificada e construir um sentido de identidade pela população no referido espaço. Com efeito, é possível reconhecer que a diversidade de atividades propostas para o espaço permite atrair um público amplo de forma ativa e agradável, sem, no entanto, comprometer a estrutura morfológica idealizada originalmente. A identidade dos espaços públicos das 700 permanece configurada no projeto da Praça Gerações, possibilitando à cidade contemporânea o diálogo com suas raízes.

\section{Referências}

ALEX, Sun. Projeto da praça: convívio e exclusão no espaço público. São Paulo: SENAC, 2008.

ANGELIS, Domingos et al. Praças: história, usos e funções. Maringá: EDUEM, 2005.

BARCELLOS, V. Q. Unidade de vizinhança: notas sobre sua origem, desenvolvimento e introdução no Brasil. Brasília: UnB, 2001. (Cadernos eletrônicos da pós-graduação)

CALABI, Donatella. Storia dell'urbanistica europea. Torino: Paravia Bruno Mondadori, 2000.

CALDAS, Igor et al. Projeto do plano piloto e quadras 700. 2013. Disponível em: <http://campus.fac.unb.br/literatura-brasiliense/item/2557-projeto-do-plano-piloto-e-quadras-700>. Acesso em: 31 jul. 2014.

CALDEIRA, Junia M. A praça brasileira, trajetória de um espaço urbano: origem e modernidade. 37p. 2007. Tese (Doutorado)- Universidade Estadual de Campinas, Campinas: UEC, 2007.

CARPINTERO, Antônio Carlos Cabral. Brasília: prática e teoria urbanística no Brasil, 1956-1998. 254p. 1998. Tese (Doutorado)-Faculdade de Arquitetura e Urbanismo, Universidade de São Paulo, São Paulo: USP, 1998.

CORREIA, R. O espaço urbano. São Paulo: Ática, 1978.

COSTA, Lúcio. Relatório do plano piloto de Brasília. Brasília: Novacap, 1957.

COSTA, Lúcio. Registro de uma vivência. São Paulo: Empresa das Artes, 1995.

FERREIRA, Marcílio M.; GOROVITZ, Matheus. A invenção da Superquadra: o conceito da unidade de vizinhança em Brasília. Brasília: IPHAN, 2009.

GEL, Jan; GEMZOE, Lars. Nuevos espacios urbanos. Barcelona: Gustavo Gili, 2002.

GRAVAGNUOLO, Benedetto. Historia del urbanismo em Europa 1750-1960. Trad. Juan Calatrava. Madrid: Akal, 1998.

GOROVITZ, Matheus. Brasília uma questão de escala. Brasília: Croqui 2, IAB-DF, 1979. 
JACOBS, Jane. Morte e vida nas grandes cidades norte-americanas. São Paulo: Martins Fontes, 2011.

RAGON, M. Histoire Mondiale de l'architecture et de l'urbanisme modernes 2: naussance de la cité moderne 19001940. Paris: Casterman, 1986a.
RAGON, M. Histoire Mondiale de larchitecture et de l'urbanisme modernes 3:de Brasília au post-modernisme 1940-1991. Paris: Casterman, 1986b.

SICA, Paolo. Storia dell'urbanistica 2: il novecento. Roma: Laterza, 1978. 